\title{
In Defence of Generalized Darwinism
}

Howard E. Aldrich, Geoffrey M. Hodgson, David L. Hull, Thorbjørn Knudsen, Joel Mokyr and Viktor J. Vanberg

howard_aldrich@unc.edu; g.m.hodgson@herts.ac.uk; david.lee.hull@etss.net; tok@sam.sdu.dk; jmokyr@northwestern.edu; viktor.vanberg@vwl.uni-freiburg.de

University of North Carolina, University of Hertfordshire, Northwestern University (Emeritus), University of Southern Denmark, Northwestern University, University of Freiburg

2 April 2008

Corresponding author and addresses for correspondence:

Geoffrey M. Hodgson, g.m.hodgson@ @erts.ac.uk

The Business School, University of Hertfordshire, De Havilland Campus, Hatfield, Hertfordshire AL10 9AB, UK

KEY WORDS: socio-economic evolution, generalized Darwinism, selection, replication,

JEL classification: B52

\begin{abstract}
Darwin himself suggested the idea of generalizing the core Darwinian principles to cover the evolution of social entities. Also in the nineteenth century, influential social scientists proposed their extension to political society and economic institutions. Nevertheless, misunderstanding and misrepresentation have hindered the realization of the powerful potential in this longstanding idea. Some critics confuse generalization with analogy. Others mistakenly presume that generalizing Darwinism necessarily involves biological reductionism. This essay outlines the types of phenomena to which a generalized Darwinism applies, and upholds that there is no reason to exclude social or economic entities.
\end{abstract}




\title{
In Defence of Generalized Darwinism
}

\author{
Howard E. Aldrich, Geoffrey M. Hodgson, David L. Hull, Thorbjørn Knudsen, Joel Mokyr
}

and Viktor J. Vanberg

\section{Introduction}

Both biology and the social sciences address diverse systems of enormous complexity. ${ }^{1}$ Historical and other empirical details will always remain of immense importance and thus we cannot expect to obtain a single explanatory theory of everything. However, as the triumph of Darwinism in biology demonstrates, it is possible to derive a powerful over-arching theoretical framework in which theorists can develop auxiliary, domain-specific explanations. This is the promise of a generalized Darwinism. Although biologists and social scientists have pointed to other important mechanisms, such as self-organization and path dependence, none of these offers a general over-arching explanatory framework for beginning to understand the evolution of all these systems. ${ }^{2}$

Darwin himself recognized the potential broader significance of his core ideas, proposing that natural selection operates upon the elements of language and that natural selection favoured tribal groups with moral and other propensities that served the common good (Darwin, 1859, pp. 422-3; 1871, vol. 1, pp. 59-61, 106, 166). Following this lead, other writers such as Walter Bagehot (1872), David Ritchie (1896), Thorstein Veblen (1899) and Albert Keller (1915) argued that the principle of selection could help explain the survival not only of individuals, but also of groups, customs, nations, business firms and other social institutions. The idea of generalizing Darwinism was later revived by V. Gordon Childe (1951), Donald T. Campbell (1965), Richard Dawkins (1976, 1983), Friedrich Hayek (1988), Daniel Dennett (1995) and others. ${ }^{3}$

Although the idea of generalizing core Darwinian principles in the social sciences has a long history, it has not proved popular. Resistance to abstract Darwinian ideas probably results from a general wariness by social scientists to the importation of concepts from biology (Degler, 1991), rather than from any adequately detailed critique of the proposal for a

1 The November 2006 issue of the Journal of Evolutionary Economics was a 'Special issue on universal Darwinism'. However, while containing critiques such as Cordes (2006), it contained no overall defence of the idea of generalizing Darwinian principles to the social or economic domain. This essay attempts to fill this gap. The authors are very grateful to Pavel Pelikan, Sidney Winter and anonymous referees for comments.

2 Leading proponents of self-organization themselves recognize this. See Kauffman (1993, p. 644) and Camazine et al. (2001, p. 89).

\footnotetext{
3 Dawkins's (1983) term 'universal Darwinism' may misleadingly suggest that Darwinism covers everything or has 'universal validity' (Dawkins, 1976, p. 205). As explained below, Darwinian principles apply to complex population systems only, notwithstanding that this covers a highly capacious set of phenomena.
} 
generalized Darwinism. Dismissals of the idea have typically been brief. We explain why such critiques are off target below.

Other critics mistakenly conflate 'universal Darwinism' with 'genetic reductionism' or 'ultra-Darwinism'. ${ }^{4}$ Although Dawkins is responsible for the term 'universal Darwinism' and is also associated with a gene-centred view of biological evolution, the idea of generalizing Darwinism is logically independent of whether or not a gene-centred view is appropriate in biology. Furthermore, generalized Darwinism does not claim that social or economic phenomena can be explained in biological terms. It is not a version of biological reductionism and logically it does not apply principally or exclusively to biology. As J. Stanley Metcalfe (1998, pp. 21-2) puts it:

That evolution is a core concept in biology does not mean that it is an inherently biological concept. Evolution can happen in other domains providing that conditions for an evolutionary process are in place. Thus, as economists applying evolutionary ideas to economic phenomena, we can learn from the debates on evolutionary biology in order to understand better the logical status of concepts such as fitness, adaptation and unit of selection without in any sense needing to absorb the associated biological context.

Contrary to the misconceptions of some its critics, the idea of generalizing Darwinism has little to do with biological metaphors or analogies. Instead of drawing analogies, which are often inexact and sometimes treacherous, generalized Darwinism relies on the claim of common abstract features in both the social and the biological world; it is essentially a contention of a degree of ontological communality, at a high level of abstraction and not at the level of detail. This communality is captured by concepts such as replication and selection, which are defined as precisely and meaningfully as possible but in a highly general and abstract sense.

What is the difference between analogy and generalization? With an analogy, phenomena and processes in one domain are taken as the reference point for the study of similar phenomena or processes in another domain. Differences are regarded as dis-analogies. On this basis, for example, social evolution is clearly dis-analogous to genetic evolution, because of the very different entities and mechanisms of replication. By contrast, for example, the Keynesian 'circular flow of income' may have some analogous features with hydraulic mechanisms, as illustrated by the famous Phillips Machine that simulates money flows through water in transparent tubes. Some theories of the business cycle use the analogy of a pendulum and thereby deploy similar differential equations. These analogical claims are different from generalizations.

Generalization in science starts from a deliberately copious array of different phenomena and processes, without giving analytical priority to any of them over others. Where possible, scientists adduce shared principles. Given that the entities and processes involved are very different, these common principles will be highly abstract and will not reflect detailed mechanisms unique to any particular domain.

For example, the laws of motion in physics apply equally to planets, rockets and billiard balls, despite huge differences of size, composition and shape. We can generalize across these

\footnotetext{
4 Rose (1997) has a long chapter entitled 'Universal Darwinism?' which very briefly (pp. 175-6) mentions memes and 'neural Darwinism' (Edelman, 1987), dismisses them without detailed criticism, and then devotes its remaining 20 pages to biological issues that have no relevance to the claim that core Darwinian principles can be applied to social entities and social evolution.
} 
domains because, at an abstract level, the same principles apply to all the phenomena, despite major differences in their features. In biology and in the social sciences, the phenomena are so complex that scientists supplement general principles by many more auxiliary and particularistic explanations, thus differentiating these sciences from physics (Mayr, 1985).

Critics of generalized Darwinism have often failed to distinguish between analogy and generalization, different levels of abstraction, and different domains of similarity or dissimilarity. Some critics have emphasized the dissimilarity between the social and biological domain (Buenstorf 2006; Cordes 2006; Nelson, 2007; Witt 2003, 2004, 2006). The claim that social and biological evolution are different at the level of detail is important and true, but ultimately irrelevant to the project of generalizing Darwinism.

Generalizing Darwinism does not rely on the mistaken idea that the mechanisms of evolution in the social and the biological world are similar in a substantive sense. Not only do natural and social evolution differ greatly in their details, but also detailed mechanisms differ greatly within the biological world. Biological organisms differ enormously in size, lifespan and reproductive fertility. Some biological species are sexually differentiated, others not. Some biological species are social, others not. Replication among invertebrates is different from that among vertebrates. To say that two sets of phenomena are similar in highly general terms does not imply that they are similar in detailed respects.

Even for biological phenomena the high degree of generality required to accommodate the full range of diversity turns out to be extensive enough to include the processes of social and cultural evolution as well (Hull, 1988, p. 403). Because the processes of selection and replication vary greatly in the biological domain, the general principles adduced from biological evolution turn out to apply to other complex phenomena as well.

The differences between the biological and the cultural domains are real and important. Cultural selection processes are different from biological selection processes. The expression of the underlying core Darwinian principles of variation, inheritance and selection differ in important ways, yet the over-arching general principles remain.

For example, Ulrich Witt $(2003,2004)$ claims that the core Darwinian principles are inappropriate for the cultural domain because of many important differences to biological reality. ${ }^{5}$ Ironically, this has led Witt to formulate a 'continuity hypothesis', according to which cultural evolution continues beyond that point within the freedom left by the constraints of Darwinian theory. As Witt (2004, pp. 131-2) writes, biological evolution has 'shaped the ground, and still defines the constraints, for ... cultural, evolution ... The historical process of economic evolution can be conceived as emerging from, and being embedded in, the constraints shaped by evolution in nature.' As far as we are aware, all proponents of generalized Darwinism would concur. ${ }^{6}$ The irony is that Witt also emphasizes a

${ }^{5}$ For a discussion of Witt's argument see Vanberg (2006).

6 Witt $(2003,2004)$ makes the point that diffusion of novelty rather than selection forces drive cultural evolution. While this point appears controversial to Witt (2003, 2004), Cordes (2006) and others, it is does not contradict general Darwinian principles. It is merely the (feasible) empirical claim that the second term of the Price equation is more important than its first term. The Price $(1970,1995)$ equation addresses changes of average fitness due to selection for a population property related to the characteristics of individual members. It shows that this population level outcome can be regarded as the sum of two distinct effects. The first term in the equation is the covariance of the individual properties and their individual fitness values, showing the extent to which possession of the property bestows fitness on individuals. The second term is a transmission effect, 
radical discontinuity between biological and social evolution, where generalized Darwinian principles apply to one but not to the other. On this point we disagree.

Admittedly, proponents of generalized Darwinism still disagree over many subsidiary points, including aspects of the precise definitions of replication and selection. It is an unfinished research project. Our essay represents a catholic view, drawing on several authors with some differences of opinion on finer points, but all upholding the possibility and importance of a generalized Darwinism. We also concur with Metcalfe (1998, p. 36) when he writes:

Nothing I have said is intrinsically a matter of biological analogy, it is a matter of evolutionary logic. Evolutionary theory is a manner of reasoning in its own right quite independently of the use made of it by biologists.

The following section addresses the types of evolving phenomena to which Darwinian principles apply. Section 3 outlines these general principles. Section 4 discusses the significance of the modern Darwinian concepts of replicator and interactor. Section 5 considers the relevance and value of a generalized Darwinism in the social sciences. The final section summarizes and concludes the argument.

\section{The ontological domain of a generalized Darwinism}

We could develop our argument in one of two ways from this point. One would be to examine inductively a number of evolutionary processes in nature and society and determine what common principles apply to them, whereas the other would be to identify some general ontological characteristics that must apply to all evolving systems. With regard to the first approach, for example, Hull et al. (2001) compare processes of evolutionary selection regarding genes, the reaction of the immune system to antigens, and operant learning. They show that deriving a general definition of selection that applies to all these processes without becoming vacuous is far from easy. Ultimately, the project to generalize Darwinism must roll up its sleeves and delve into such empirical issues.

Unfortunately, the application of Darwinian principles to social or economic evolution has been impaired by a lack of consensus concerning what is actually selected or replicated. Richard Dawkins (1976) famously dubbed the unit of cultural evolution as a 'meme'. However, disputes have raged concerning the nature of a meme and no consensus has emerged.

One legitimate reaction to this impasse would be to adopt the strategy described above and empirically compare many processes of social selection and replication, in an attempt to induce common general principles. However, a lack of consensus among evolutionary social scientists means that few commonly accepted domains and entities have been identified as a basis for comparison.

With regard to the second approach, we can accept that at some later stage, detailed comparisons will be essential, but in the interim we can make progress by approaching the

whereby changing properties of existing individuals lead to modifications of their individual fitnesses, such as through innovation or learning. With the first effect the population changes through selection; with the second effect the change comes through the transformations of individuals or entities. Witt and Cordes suggest that the second effect is more important. This is a matter of empirical enquiry and not a test of the principles of generalized Darwinism. Indeed, without Darwinian selection there would be no way of removing useless novelties (Pavel Pelikan, private correspondence). 
problem from the other end. Instead of working upwards from detail to generality, it is possible to consider some general ontological characteristics that must apply to the relevant systems and populations under consideration. We describe the relevant phenomena as 'complex population systems'.?

The term refers to both biological and social phenomena. By outlining the general, shared features of complex population systems we identify the ontological communality to which we referred above. We posit that all complex population systems can be analysed in terms of general Darwinian principles. The systems considered here involve populations of entities. Populations are defined by members of a type that are similar in key respects, but within each type there is some degree of variation, due to genesis or circumstances. ${ }^{8}$

We assume that entities within these populations have limited capacities to consume some materials and energy from their environment and they have gained the use of mechanisms with which to process some information useful for survival. These entities may or may not have a developed brain or memory. They may or may not be capable of reflecting on their circumstances and remembering past or imagining future behaviours.

All these entities are mortal and degradable, and they need to consume materials and energy in order to survive or minimize degradation. However, because they do not have access to all environmental resources at once, these entities face an omnipresent problem of local and immediate scarcity, as well as the possibility of binding resource constraints. ${ }^{9}$ These circumstances present specific problems that the entities must solve to minimize degradation and raise their chances of survival. In short, these entities are engaged in a struggle for existence, to use the term adopted by Darwin (1859, pp. 62-63).

Finally, we assume some capacity to retain and pass on to others workable solutions to problems they have faced. The advantages of retaining such problem solutions or adaptations are obvious in avoiding the risks and costs of learning them anew. We assume that the entities possess some capacity to pass on to others information about such workable solutions, providing the foundation for a trans-generational cumulative growth of problem-solving 'knowledge.'

This is the basis of the Darwinian principle of inheritance, which refers to a broad class of mechanisms, including those of 'replication' and 'descent' (Mayr 1991), by which information concerning adaptations is retained, preserved, passed on or copied through time.

In sum, a complex population system involves populations of non-identical (intentional or non-intentional) entities that face locally scarce resources and problems of survival. The entities retain some adaptive solutions to such problems and may pass them on to other entities. Examples of populations in such systems are plentiful both in nature and in human society. They include every biological species, from amoeba to humans. They would include self-replicating automata, of the type discussed by John von Neumann (1966). In addition,

\footnotetext{
7 This account of complex population systems makes use of material from Hodgson and Knudsen (2006a), where some further details of the argument appear.
}

8 See Mayr (1976, p. 28; 1982, pp. 46f.) for a discussion of the contrast between 'population thinking' and the outlook of the 'typologist.'

${ }^{9}$ See Hodgson and Knudsen (2006a, p. 4) for a discussion of this specific concept of scarcity. 
and importantly for the social scientist, they include human institutions, as long as we regard institutions as cohesive entities having some capacity for the retention and replication of problem solutions.

In this manner, the common ontological features of all complex population systems, including in nature and human society, are established, without ignoring the huge differences of detail between them.

\section{The core Darwinian principles}

Having sketched in broad terms the type of evolutionary system we are considering, it becomes evident that the evolution of such a system must involve the three Darwinian principles of variation, selection and retention (Campbell, 1965). These abstract principles do not themselves provide all the necessary details, but nevertheless they must be honoured, for otherwise the explanation of evolution will be inadequate.

Consider the three Darwinian principles in turn. First, there must be some explanation of how variety is generated and replenished in a population. In biological systems the answers established since Darwin's death - involve genetic recombination and mutations. By contrast, the evolution of social institutions involves imitation, planning and other mechanisms very different from the detailed processes found in biology (Aldrich and Ruef 2006). The general problem of the existence and replenishment of variety remains a vital question of evolutionary research in the social and technological domain (Metcalfe 1998, Nelson 1991, Saviotti 1996).

Second, there must be an explanation for how useful information concerning solutions to particular adaptive problems is retained and passed on. This requirement follows directly from our assumptions concerning the broad nature of complex population systems, wherein there must be some mechanism by which adaptive solutions are copied and passed on. In biology, these mechanisms often involve genes and DNA. In social evolution, we may include the replication of habits, customs, rules and routines, all of which may carry solutions to adaptive problems. Some mechanism must exist that ensures that some such solutions endure and replicate; otherwise the continuing retention of useful knowledge would not be possible (Vanberg 1994).

Third, and not least, there must be an explanation of the fact that entities differ in their longevity and fecundity. In given contexts, some entities are more adapted than others, some survive longer than others, and some are more successful in producing offspring or copies of themselves. Here we invoke the principle of selection. Briefly, selection involves an anterior set of entities, each interacting with its environment and somehow being transformed into a posterior set where all members of the posterior set are sufficiently similar to some members of the anterior set, and where the resulting frequencies of posterior entities depend upon their properties in the environmental context (Price, 1970, 1995). Through selection, a set of entities, a population, will gradually adapt in response to the criteria defined by an environmental factor.

Although this is a broad definition of selection, it is nevertheless sharp enough to distinguish itself from the principle of variation. The latter requires some explanation of the sources and replenishments of variety. Selection refers to the mechanisms that bring about the survival of some variations rather than others, often reducing variety. Even when both varietycreation and selection involve human agency, as often is the case in the human domain, the 
two processes are quite distinct. Innovation is about the creation of new variations, whereas selection is about how they are tested in the real world.

Note that the outcomes of a selection process are necessarily neither moral nor just, even though as politically organized communities, humans may impose moral constraints on social processes by adopting 'rules of the game' or institutional provisions that replace 'natural selection' by 'artificial' or 'purposeful' selection (Commons 1934; Vanberg 1997; Hodgson 2004a). Furthermore, there is no requirement that the outcomes of a selection process be necessarily optimal or an improvement on their precursors. Insofar as these outcomes carry connotations of refinement or efficiency, it is efficiency relative to the given environment, and efficiency that is tolerable rather than optimal. Darwinism does not assume that selection brings about globally efficient or (near) optimal outcomes, and in certain instances, selection can even lead to systematic errors or maladaptions (Hodgson 1993; Hull 2001).

Without the principle of selection, we have no way of explaining how some entities or their offspring prevail over others. The principle is widely held to apply in the natural world; some members of a species often have greater chances of survival and procreation. This helps to explain how species, over the long term, become adapted to their environment. Note that the move from the natural to the social world does not undermine the principle of selection. Even if there is not a fierce life-and-death struggle between rival customs or institutions, some explanation is required of why some enjoy greater longevity than others, why some are imitated more than others, and why some diminish and decline. Any such explanation must come under the general rubric of selection, as defined above.

Overall, as long as there is a population within which entities display variation in the acquisition of characteristics vital to survival, then Darwinian evolution will occur. However, Darwin's principles of evolution do not themselves provide a complete explanation. Darwinism does not provide a complete theory of everything, from cells to human society. Instead, these principles are a kind of 'meta-theory', or an over-arching theoretical framework wherein theorists place particular explanations. Crucially, explanations additional to natural selection are always required to explain any evolved phenomenon. For example, natural selection alone cannot explain why some birds have dull and others colourful plumage. Different auxiliary explanations are required, such as camouflage against predators in some cases, or competition for mates and sexual selection in others. Selection is a general principle, but it operates in different ways in different contexts. Likewise, the general Darwinian principle of variation applies, but it does not itself explain how variation occurs.

To repeat: acknowledging the role of Darwinian principles in social evolution does not imply that the detailed mechanisms of selection, variation and inheritance are analogous or similar. Consequently, the application of general Darwinian principles cannot do all the explanatory work for the social scientist. Darwinism alone is not enough.

Accordingly, the use of these general Darwinian principles does not mean any neglect of other features or mechanisms at the level of detail. The use of these principles does not amount to the kind of generalization where specific important features or additional processes are neglected. On the contrary they remain vital for the explanation.

\section{Replicators and interactors}

Modern Darwinian theory makes a distinction between 'replicators' and 'interactors' (Hull, 1988). A number of authors have developed and refined the definition of a replicator. An 
emerging consensus argues that replication involves a causal relationship between two or more entities, where there is substantial similarity between the original and replicated entities, and where information concerning adaptive solutions to survival problems is passed from one set of entities to another (Sterelny et al. 1996; Godfrey-Smith 2000; Sperber 2000). The definitional characteristics of causality, similarity and information transfer are common to these accounts.

However, the consensus definition requires further refinement. Furthermore, there are very different types of replicators, even in the biological domain. For example, prions are widely regarded as replicators. Prions involve the accumulation of an abnormally folded variant of the normal prion protein, which spreads by direct contact through which the normal form also becomes misfolded and thus converted to an abnormal and equally infectious form (Prusiner, 1998). By contrast, DNA contains information in its molecular structure that conditions the growth and behaviour of organisms. Unlike the prion, DNA involves context-responsive construction mechanisms that hold adaptive information attuned to past environments. Consequently, there may be different types of biological replicators, where DNA is a more sophisticated variant permitting the transfer of richer and more complex information (Szathmáry 2000; Hodgson and Knudsen 2008). ${ }^{10}$

A consequence of this observation regarding diversity among replicators is that when we consider the social world, the possibility of different types of replicators emerges. None will be similar in detail or mechanism to DNA. If they exist, those social replicators that involve context-responsive construction mechanisms holding adaptive information will constitute a rather special and important case. The existence of social replicators cannot be denied simply because DNA-like mechanisms are absent.

Turning to the interactor, this has been defined as 'an entity that directly interacts as a cohesive whole with its environment in such a way that this interaction causes replication to be differential' (Hull 1988, p. 408). Some theorists have suggested enhancements of this definition (Hodgson and Knudsen 2004b). Furthermore, more work is necessary to show how the interactor relates to the replicator, especially if multiple levels of replication or interaction occur.

Clearly, there are cohesive evolving entities, in both the biological and social domains, such as organisms and organizations. The question arises as to whether such entities in the social world interact with their environments in ways that cause the differential replication of relevant stored information. If we consider economic competition between firms, then the elimination of some and the prosperity of others leads to the differential copying (by collaboration or imitation) of routines, techniques, management procedures, and so on (Nelson and Winter, 1982; Aldrich and Ruef 2006). If any of these elements qualify as social replicators, then clearly they are very different from biological replicators such as genes. There are crucial differences concerning how the information is stored, how it is replicated, and how faithful is the replication. The general definition of a replicator has to be deployed with care. Nevertheless, there is at least a prime facie case for identifying interactors and replicators in the social domain.

Although so far there is no consensus on what social replicators or interactors are, three of us have argued that business firms are examples of social interactors, and individual habits

10 The general concept of information itself requires clarification in this context and has been subject to some debate. See for example Maynard Smith (2000a, 2002b), Griffiths (2001) and Godfrey-Smith (forthcoming). 
and organizational routines qualify as replicators (Aldrich and Ruef 2006; Hodgson and Knudsen 2004b, 2006b, 2008). Other Darwinian theorists consider individuals or groups as interactors, and ideas as social or cultural replicators (Hull 1988; Mokyr 2006). These debates remain important among proponents of a generalized Darwinism.

Some critics claim that a sharp replicator-interactor distinction is unviable or inappropriate in social evolution. It is interesting that they share this stance with other, quite different, theorists. The subset of evolutionary economists who resist a generalized Darwinism, exclusively gene-centred theorists, and biological reductionists, all deny the existence of social replicators (i.e. social entities that are copied in some way and conform to the general definition of a replicator).

The distinction between replicators and interactors, their clear definition, and the discussion of different types of each, are important for further reasons. They are vital to distinguish between more superficial cases of contagion or diffusion, on the one hand, and more meaningful replication or inheritance on the other. For example, the spread of laughter or some fashions, are examples of diffusion that often do not necessarily involve inheritance. Diffusion may mean little more than the reception of a signal that triggers behaviour according to existing dispositions. For replication to occur, significant developmental dispositions and capacities must be copied that are new to the recipient, and these new capacities must themselves be capable of replication. An important feature of some replicators is that by the copying of such capacities they have the potential to increase the level of complexity in the system as a whole (Hodgson and Knudsen, 2008). ${ }^{11}$

If there were no social replicators, then the principles of generalized Darwinism suggest that there is no mechanism in social evolution by which information concerning adaptations to the environment can be copied with some degree of fidelity through time. This would further imply that social evolution is less sophisticated than biological evolution, and has a more limited potential for the evolution of more complex phenomena. We see no reason at this stage to accept the premise of this argument. We assert that there is at least a prima facie case for identifying interactors and replicators in the social domain.

Some critics fall prey to the unfounded assumption that unitary persistence, associated with high fidelity replication, is a necessary condition for selection to work. We do not have to establish that social replicators copy their information as reliably as genes (they certainly do not) in order to identify social replicators. As Stephen Jay Gould (2002) argued, it is plurifaction that matters, i.e. the increase in relative representation of a bundle of heritable attributes. Whether or not plurifaction happens by hi-fidelity replication is besides the point.

While the replication of behaviour seems uncontroversial, it has recently been argued that the notions of replication and replicators are inappropriate for studying the spread of cognitive frames and representations (Atran, 2001, 2002; Boyer, 1994, 1999; Sperber, 1996). According to these critics, cognitive representations are non-discrete, cultural transmission is very inaccurate and therefore favours diversity over convergence, and strong cognitive attractors in

11 The replicator-interactor distinction also relates to the question of Lamarckism, which typically is taken to mean the inheritance of acquired characteristics. The replicator-interactor distinction is necessary to establish adequately the concept of inheritance in this context (Hull, 1982; Hodgson and Knudsen, 2006b). Consequently, whether true or not, claims that social evolution is Lamarckian depend on a replicator-interactor distinction. Notably, Darwinism and Lamarckism are not mutually exclusive: Darwin (1859) himself believed in Lamarckian inheritance. However, Lamarckism alone is inadequate because it cannot explain why dysfunctional acquired characteristics are inherited without the invocation of a selection mechanism (Dawkins, 1983). 
any case swamp the influence from selection forces. Even though cultural evolution is commonly non-discrete, low fidelity and strongly affected by cognitive processes, these observations are entirely an empirical matter. Joseph Henrich and Robert Boyd (2002) convincingly demonstrate that continuous attractors often reduce to the standard discrete replicator model and low fidelity replication does not preclude adaptation or accumulation at the cultural level.

Our discussion in this section shows how the idea of a generalized Darwinism can be extended to help obtain important propositions concerning the general nature of evolution in complex population systems and how they apply in particular to evolution in human society. We have also highlighted recent work that demonstrates the usefulness of the Darwinian principles under conditions that are commonly ascribed to the social domain, i.e. noisy replication and possibly continuous traits. The following section explores further implications for our understanding of social evolution.

\section{Generalized Darwinism - its relevance and importance}

Appropriate generalization is at the core of all scientific endeavours. However, generalization should not go so far as to become vacuous. We believe that a generalized Darwinism sustains important substantial propositions that have application and relevance to evolution in human societies. We have already given some reasons for this claim. We add further supporting arguments below.

There are a number of advantages of a general analysis of selection processes that builds on core Darwinian principles. It provides a focus for inquiry and enables a more systematic accumulation and organization of knowledge pertaining to a wider array of selection processes. A generalized Darwinism offers a broad definition of selection within which we can classify and compare different types of selection process. Even at an abstract level, two basic types of selection can be distinguished, namely subset and generative selection (Hodgson and Knudsen, 2006c). Further subdivisions and classifications are clearly possible, according to both mechanisms and outcomes. For instance, the George Price $(1970,1975)$ general definition of selection allows the diffusion of information or other features as a special case, but excludes random outcomes such as drift.

Furthermore, as Hull et al. (2001) demonstrate, a generalized Darwinism can lead to comparative analyses of selection processes across empirical domains. We see a strong possibility that such empirical comparisons will lead to further revisions and refinements of our understanding of general selection principles. This is an important agenda for future research.

For social scientists, the application of Darwinian ideas to social phenomena has important implications concerning the rationality and psyche of human agents. Assumptions concerning human agents must be susceptible to causal explanation, and be consistent with general Darwinian principles and our understanding of human evolution. These implications have been long acknowledged by a number of philosophers, psychologists and social scientists (James, 1890; Dewey, 1910; Veblen, 1914; Richards, 1987).

One of these arguments concerns the concept of rationality. Darwin (1974, pp. 84, 115) himself wrote in 1856: "Men are called "creatures of reason," more appropriately they would be "creatures of habit." Although Darwin did not elaborate further, we can draw out some of the implications from a generalized Darwinism. 
The principles of generalized Darwinism focus on the development, retention and selection of information concerning adaptive solutions to survival problems faced by organisms or other relevant entities in their environment. The storage and replication of such information is a general feature of complex population systems. When we apply this framework to particular cases, questions naturally arise concerning the nature, mechanisms and material substrate of these adaptive solutions. Relevantly, the biologist and philosopher Ernst Mayr (1988) developed the concept of 'program-based behaviour' involving sets of conditional, rule-like dispositions, linked together into what he termed "programs." 12 Instincts and biological genotypes involve programs. Human ideas, habits and customs can also have program-like qualities. Sophisticated replicators carry such behavioural programs. Generalized Darwinisn highlights their importance in evolutionary processes.

Darwinism is successful because it supplies a framework for causal explanation of the evolution of complex, undesigned outcomes. Accordingly, Darwinism constantly raises questions of causality and requires explanations of origin. This applies in particular to the dispositional programs behind human behaviour. The consequences for the social sciences are important. Instead of simply assuming that agents hold beliefs and preferences, the paradigm of program-based behaviour requires an explanation of their evolutionary emergence, through both natural selection and individual development. Evolution involves both the adaptation of programs to changing circumstances and the elimination of other programs through selection.

The conventional rational actor model in the social sciences simply sets out assumptions that are consistent with a set of behaviours. By contrast, the paradigm of program-based behaviour focuses on the explanation of the dispositions behind any act. The concept of the program may be subdivided between programs that do and do not involve deliberation or conscious prefiguration. The paradigm of program-based behaviour has been applied to economics by Vanberg $(2002,2004)$ and has strong similarities with John Holland's (1995) theory of adaptive agents. This paradigm is more adequate than the primary focus on rationality and beliefs. The related concept of habit - as a particular form of a program - has also been revisited and refined in this evolutionary context (Hodgson and Knudsen, 2004a).

A generalized Darwinism provides a framework in which particular (non-universal) evolutionary patterns and mechanisms can readily be considered. One example of this is the wider use of Niles Eldredge's and Stephen Jay Gould's (1977) concept of 'punctuated equilibria'. Within biology, this concept has attracted some criticism and debate (Somit and Peterson, 1992). Some scholars have misinterpreted it as a challenge to core Darwinian principles. It is not. Instead, a viable concept of punctuated equilibria posits that under specific conditions, Darwinian evolutionary processes can sometimes dramatically accelerate, and the whole system can shift relatively rapidly from one chaotic attractor to another. A number of authors have applied the concept of punctuated equilibria to social, organizational, institutional, political, cultural, economic and technological evolution. ${ }^{13}$ The viability of this concept in specific circumstances depends on not only a reconciliation with the framework of generalized Darwinism but also an examination of the specific mechanisms of replication and selection that have the potential to generate such dramatic shifts in the pattern of evolution.

12 In important respects the idea of 'program-based behavior' was foreshadowed by Simon (1957) in his famous work on bounded rationality (March and Simon, 1958; Vanberg, 2002, pp. 24 ff.).

13 See Miller and Friesen (1980), Tushman and Romanelli (1985), Collins (1988), Krasner (1988), Hannan and Freeman (1989), Mokyr (1990), Gersick (1991), Gowdy (1993), Aoki (2001) and others. 
Crucially, Darwinism focuses our attention on the possible mechanisms through which variety is preserved and created. It is remarkable that two of the most important mechanisms identified by Darwin (1859) and retained in modern biology depend on locational considerations. First, the migration of a group to another area with a different physical environment, and second the use or creation of different niches, remain two of the most important mechanisms to explain speciation. Related ideas would seem to transfer directly to the social or economic domain, for example with the creation of new products or industries in different geographical and institutional contexts. In these cases the new environment, and the (relative) isolation of a group from the majority, create new opportunities for variation.

As the population becomes subdivided into (relatively) isolated subsets, small mutations can have bigger overall effects for the population as a whole. Furthermore, the different environments require different fitness characteristics for survival. New species may emerge as a result of physical separation or the demands of different environments.

Crucially, similar arguments apply to human institutions as well as biological organisms, notwithstanding the fact that the nature and mechanisms of mutation and separation are very different. The general ideas of mutation and physical separation particularly apply to the evolution of languages and all sorts of customs. For example, relative isolation and language change leads to subdivision and often the creation of new languages.

In addition, there is now a growing literature on how firms may perform differently in different contexts, such as under different regulatory regimes or among different types of financial institutions (Amable, 2000; Aoki, 2001; Hall and Soskice, 2001; Boyer, 2005; Kenworthy, 2006).

The above examples show how the framework of a generalized Darwinism can be helpful in organizing and promoting specific research programmes in the social domain. A generalized Darwinism does not itself provide all the answers. For example, it neither specifies the detailed sources of variation nor explains individual innovations. Nevertheless, it identifies essential evolutionary mechanisms in a general form, particularly concerning replication, selection and the impact of variation. Applied rigorously, it forces authors to be specific and precise in defining units of analysis. It also forces analysts to be historical, because no matter what the exact set-up or units of analyses are, such an evolutionary analysis forces attention on processes going back into the past, their built-in tendencies to persist (through 'replication') and how the present is created as variations on the past. In that sense, all social scientists relying on this framework will be forced to take history into account (Mokyr, 1996).

By itself, a generalized Darwinism is insufficient to provide a complete answer, but it provides a general framework in which additional and context specific explanations may be placed. Its further usefulness depends on additional and extensive work. Despite several earlier and partial starts, the research programme is still in its infancy.

\section{Summary and conclusions}

Evolutionary theory has for a century been viewed by many scholars to be highly useful to economics (Nelson, 1995; Metcalfe, 1998), but it has sometimes been resisted because of a confusion between a general theory of change and sometimes unsuccessful attempts to shoehorn concepts or analogies from biology into economics. As we have insisted above, the 
idea of generalizing Darwinism is not about analogies and does not depend on the proposition that the detailed mechanisms of social and biological evolution are similar. They are certainly not. Furthermore, the mechanisms of selection and replication are very different between different entities within the biological domain. Consequently we should expect considerable evolutionary differences of entity and mechanism both (a) between nature and society and (b) within society itself. Instead of detailed similarity, the idea of generalizing Darwinism depends on a degree of ontological communality at a highly abstract level. This communality is captured by the broad idea of a complex population system and the formulation of highly general concepts of selection and replication.

Proposals for a generalized Darwinism are also unaffected by the claim that Darwinism, or the principles of selection, inheritance and variation are inadequate to explain social evolution. They are definitely inadequate. They are also insufficient to explain detailed outcomes in the biological sphere. In neither domain are these core Darwinian principles sufficient. In both cases auxiliary principles are required. However, none of this undermines the validity of generalization at an abstract level. Insufficiency does not amount to invalidity. Furthermore, given the existence of complex population systems in both nature and society, a generalized Darwinism is the only over-arching framework we have for placing detailed specific mechanisms.

Given these rebuttals, how could one criticize the idea of generalizing Darwinism? Critics could argue that the ontology of complex population systems does not apply to socioeconomic evolution. Alternatively, critics could attempt to show that explanations of complex population systems do not require the Darwinian principles of variation, inheritance or selection. Finally, the critics could apply the rigorous definitions of variation, inheritance and selection to socio-economic phenomena and show that the outcomes are not particularly meaningful or useful. The idea of generalizing Darwinism is not immune to criticism, but previous critiques have generally been misconceived or misplaced.

We hypothesize that much of the resistance to the idea of generalizing Darwinism to include social evolution stems from an ingrained suspicion of social scientists to ideas from biology. Students in the social sciences are repeatedly warned against 'social Darwinism' and any idea of explaining human behaviour in terms of genes. Not only are the issues more complex than the students are often told, but also the idea of generalizing Darwinism has nothing to do with standard (and often dubious) accounts by social scientists of 'social Darwinism', 'sociobiology' or 'genetic reductionism'. ${ }^{14}$

We urge that the idea of generalizing Darwinism not be confused with 'genetic reductionism' and other aforementioned ideas. On the contrary, many opponents of a generalized Darwinism have something in common with the reductionists they likewise eschew. Gene-centred theorists, biological reductionists, and those evolutionary economists who resist a generalized Darwinism all deny the existence of replicators at a social level. An adequately formulated generalized Darwinism sustains replication and selection on multiple levels and resists rather than endorses biological reductionism.

On the other hand, the idea of generalizing Darwinism to socio-economic evolution challenges the longstanding idea among social scientists that social and biological phenomena should be completely partitioned, that social scientists have little to learn from biology, and

\footnotetext{
14 See Bannister (1979) and Hodgson (2004b) on social Darwinism, and Segerstråle (2000) on the reactions of social scientists to sociobiology.
} 
vice versa. A generalized Darwinism is consistent with the idea that human society is embedded in the natural world and depends upon it for its survival.

We have also argued here that a generalized Darwinism sustains important, non-vacuous propositions that are highly relevant to the evolution in human societies, while other auxiliary explanations are also required. A generalized Darwinism systematizes the process of empirical inquiry and organizes detailed knowledge pertaining to a wide variety of evolutionary processes.

Furthermore, Darwinian ideas have important implications for social scientists concerning the rationality and psyche of human agents. Assumptions concerning human agents must be consistent with our understanding of human evolution. Darwinian evolution involves the development, retention and selection of information concerning adaptive solutions to survival problems faced by organisms in their environment. Darwinism constantly raises questions of causality and requires explanations of origin. This applies in particular to the dispositional programs behind human thought and behaviour.

Overall, Darwinism by itself is insufficient to provide full and complete answers, but it provides a general framework in which additional and context specific explanations may be placed. Its further usefulness depends on additional and extensive work. Despite several earlier historical efforts, this research programme is still at the stage of elucidating the key concepts involved. We are also entering an exciting phase of detailed empirical application. We welcome others to join in these efforts.

\section{References}

Aldrich, Howard E. and Ruef, Martin (2006) Organizations Evolving, $2^{\text {nd }}$ edition (London: Sage Publications).

Amable, Bruno (2000) 'Institutional Complementarity and Diversity of Social Systems of Innovation and Production', Review of International Political Economy, 7(4), Winter, pp. 645-87.

Aoki, Masahiko (2001) Toward a Comparative Institutional Analysis (Cambridge, MA: MIT Press).

Atran, Scott (2001) 'The Trouble with Memes: Inference versus Imitation in Cultural Creation', Human Nature, 12(4), pp. 351-381.

Atran, Scott (2002) In Gods we Trust: The Evolutionary Landscape of Religion (Oxford and New York: Oxford University Press).

Bagehot, Walter (1872) Physics and Politics, or, Thoughts on the Application of the Principles of 'Natural Selection' and 'Inheritance' to Political Society (London: Henry King).

Bannister, Robert C. (1979) Social Darwinism; Science and Myth in Anglo-American Social Thought (Philadelphia: Temple University Press).

Boyer, Pascal (1994) The Naturalness of Religious Ideas (Berkeley: University of California Press). 
Boyer, Pascal (1999) 'Cognitive Tracks of Cultural Inheritance: How Evolved Intuitive Ontology Governs Cultural Transmission’, American Anthropologist, 100(4), pp. 876-889.

Boyer, Robert (2005) 'Coherence, Diversity, and the Evolution of Capitalisms - The Institutional Complementarity Hypothesis', Evolutionary and Institutional Economics Review, 2(1), October, pp. 43-80.

Buenstorf, Guido (2006) 'How Useful is Generalized Darwinism as a Framework to Study Competition and Industrial Evolution?', Journal of Evolutionary Economics, 16(5), December, pp. 511-27.

Camazine, Scott, Deneubourg, Jean-Luis, Franks, Nigel R., Sneyd, James, Theraulaz, Guy, and Bonabeau, Eric (2001) Self-Organization in Biological Systems (Princeton, NJ: Princeton University Press).

Campbell, Donald T. (1965) 'Variation, Selection and Retention in Sociocultural Evolution', in Barringer, H. R., Blanksten, G. I. and Mack, R. W. (eds) (1965) Social Change in Developing Areas: A Reinterpretation of Evolutionary Theory (Cambridge, MA: Schenkman), pp. 19-49.

Childe, V. Gordon (1951) Social Evolution (London: Watts).

Collins, Randall (1988) Theoretical Sociology (San Diego, CA: Harcourt, Brace, Jovanovich).

Commons, John R. (1934) Institutional Economics - Its Place in Political Economy (Madison: The University of Wisconsin Press).

Cordes, Christian (2006) 'Darwinism in Economics: From Analogy to Continuity', Journal of Evolutionary Economics, 16(5), December, pp. 529-41.

Darwin, Charles R. (1859) On the Origin of Species by Means of Natural Selection, or the Preservation of Favoured Races in the Struggle for Life (London: Murray).

Darwin, Charles R. (1871) The Descent of Man, and Selection in Relation to Sex, $1^{\text {st }}$ edn., 2 vols (London: Murray and New York: Hill).

Darwin, Charles R. (1974) Metaphysics, Materialism, and the Evolution of Mind: Early Writings of Charles Darwin, transcribed and annotated by Paul H. Barrett with a commentary by Howard E. Gruber (Chicago: University of Chicago Press).

Dawkins, Richard (1976) The Selfish Gene (Oxford: Oxford University Press).

Dawkins, Richard (1983) 'Universal Darwinism', in D. S. Bendall (ed.) (1983) Evolution from Molecules to Man (Cambridge: Cambridge University Press), pp. 403-25.

Degler, Carl N. (1991) In Search of Human Nature: The Decline and Revival of Darwinism in American Social Thought (Oxford and New York: Oxford University Press).

Dennett, Daniel C. (1995) Darwin's Dangerous Idea: Evolution and the Meanings of Life (London and New York: Allen Lane, and Simon and Schuster).

Dewey, John (1910) The Influence of Darwin on Philosophy and Other Essays in Contemporary Philosophy (New York: Holt).

Edelman, Gerald M. (1987) Neural Darwinism: The Theory of Neuronal Group Selection (New York: Basic Books). 
Gersick, Connie J. G. (1991) 'Revolutionary Change Theories: A Multilevel Exploration of the Punctuated Equilibrium Paradigm', Academy of Management Review, 16(1), January, pp. 10-36.

Godfrey-Smith, Peter (2000) 'The Replicator in Retrospect', Biology and Philosophy, 15, pp. 403-23.

Godfrey-Smith, Peter (forthcoming) 'Information in Biology' in Hull, David L. and Ruse, Michael (eds) The Cambridge Companion to the Philosophy of Biology (Cambridge and New York: Cambridge University Press).

Gould, Stephen Jay (2002) The Structure of Evolutionary Theory (Cambridge, MA: Harvard University Press).

Gowdy, John M. (1993) 'The Implications of Punctuated Equilibria for Economic Theory and Policy', Methodus, 5(1), June, pp. 111-3.

Griffiths, Paul E. (2001) 'Genetic Information: A Metaphor in Search of a Theory', Philosophy of Science, 68(3), September, pp. 394-412.

Eldredge, Niles and Gould, Stephen Jay (1977) 'Punctuated Equilibria: The Tempo and Mode of Evolution Reconsidered', Paleobiology, 3, pp. 115-51.

Hall, Peter A. and Soskice, David (2001) Varieties of Capitalism: The Institutional Foundations of Comparative Advantage (Oxford: Oxford University Press).

Hannan, Michael T. and Freeman, John (1989) Organizational Ecology (Cambridge, MA: Harvard University Press).

Hayek, Friedrich A. (1988) The Fatal Conceit: The Errors of Socialism. The Collected Works of Friedrich August Hayek, Vol. I, ed. William W. Bartley III (London: Routledge).

Henrich, Joseph and Boyd, Robert (2002) 'On Modeling Cognition and Culture - Why Cultural Evolution Does Not Require Replication of Representations', Journal of Cognition and Culture, 2(2), pp. 87-112.

Hodgson, Geoffrey M. (1993) Economics and Evolution: Bringing Life Back Into Economics (Cambridge, UK and Ann Arbor, MI: Polity Press and University of Michigan Press).

Hodgson, Geoffrey M. (2004a) The Evolution of Institutional Economics: Agency, Structure and Darwinism in American Institutionalism (London and New York: Routledge).

Hodgson, Geoffrey M. (2004b) 'Social Darwinism in Anglophone Academic Journals: A Contribution to the History of the Term', Journal of Historical Sociology, 17(4), December, pp. 428-63.

Hodgson, Geoffrey M. and Knudsen, Thorbjørn (2004a) 'The Complex Evolution of a Simple Traffic Convention: The Functions and Implications of Habit', Journal of Economic Behavior and Organization, 54(1), pp. 19-47.

Hodgson, Geoffrey M. and Knudsen, Thorbjørn (2004b) 'The Firm as an Interactor: Firms as Vehicles for Habits and Routines', Journal of Evolutionary Economics, 14(3), July, pp. 281-307.

Hodgson, Geoffrey M. and Knudsen, Thorbjørn (2006a) 'Why We Need a Generalized Darwinism: and Why a Generalized Darwinism is Not Enough', Journal of Economic Behavior and Organization, 61(1), September, pp. 1-19. 
Hodgson, Geoffrey M. and Knudsen, Thorbjørn (2006b) 'Dismantling Lamarckism: Why Descriptions of Socio-Economic Evolution as Lamarckian are Misleading', Journal of Evolutionary Economics, 16(4), October 2006, pp. 343-66.

Hodgson, Geoffrey M. and Knudsen, Thorbjørn (2006c) 'The Nature and Units of Social Selection', Journal of Evolutionary Economics, 16(5), December 2006, pp. 477-89.

Hodgson, Geoffrey M. and Knudsen, Thorbjørn (2008) 'Information, Complexity and Generative Replication', Biology and Philosophy, 43(1), pp. 47-65.

Holland, John H. (1995) Hidden Order: How Adaptation Builds Complexity (Reading: Helix Books).

Hull, David L. (1982) 'The Naked Meme', in Henry C. Plotkin (ed.) (1982) Learning, Development and Culture: Essays in Evolutionary Epistemology (New York: Wiley), pp. 273-327.

Hull, David L. (1988) Science as a Process: An Evolutionary Account of the Social and Conceptual Development of Science (Chicago: University of Chicago Press).

Hull, David L., Langman, Rodney E., and Glenn, Sigrid S. (2001) 'A General Account of Selection: Biology, Immunology and Behavior', Behavioral and Brain Sciences, 24(3), June, pp. 511-73.

James, William (1890) The Principles of Psychology, 2 vols, 1st edn. (New York and London: Holt and Macmillan).

Kauffman, Stuart A. (1993) The Origins of Order: Self-Organization and Selection in Evolution (Oxford and New York: Oxford University Press).

Keller, Albert Galloway (1915) Societal Evolution: A Study of the Evolutionary Basis of the Science of Society (New York: Macmillan).

Kenworthy, Lane (2006) 'Institutional Coherence and Macroeconomic Performance', SocioEconomic Review, 4(1), January, pp. 69-91.

Henrich, Joseph and Boyd, Robert (2002) 'On Modeling Cognition and Culture - Why Cultural Evolution Does Not Require Replication of Representations', Journal of Cognition and Culture, 2(2), pp. 87-112.

Krasner, Stephen (1988) 'Sovereignty', Comparative Political Studies, 21, pp.64-94.

March, James G. and Simon, Herbert A. (1958) Organizations (New York: Wiley).

Maynard Smith, John (2000a) 'The Concept of Information in Biology', Philosophy of Science, 67(2), June, pp. 177-194.

Maynard Smith, John (2000b) 'Reply to Commentaries', Philosophy of Science, 67(2), June, pp. 214-218.

Mayr, Ernst (1976) Evolution and the Diversity of Life (Cambridge, MA: Harvard University Press).

Mayr, Ernst (1982) The Growth of Biological Thought (Cambridge, MA: Harvard University Press).

Mayr, Ernst (1985) 'How Biology Differs from the Physical Sciences', in Depew, David J. and Weber, Bruce H. (eds) (1985a) Evolution at a Crossroads: The New Biology and the New Philosophy of Science (Cambridge, MA: MIT Press), pp. 43-63. 
Mayr, Ernst (1988) Toward a New Philosophy of Biology: Observations of an Evolutionist (Cambridge, MA and London: Harvard University Press).

Mayr, Ernst (1991) One Long Argument: Charles Darwin and the Genesis of Modern Evolutionary Thought (Cambridge, MA and London: Harvard University Press and Allen Lane).

Metcalfe, J. Stanley (1998) Evolutionary Economics and Creative Destruction (London and New York: Routledge).

Miller, Danny and Friesen, Peter H. (1980) 'Momentum and Revolution in Organizational Adaptation', Academy of Management Journal, 23, pp. 591-614

Mokyr, Joel (1990) 'Punctuated Equilibria and Technological Progress', American Economic Review (Papers and Proceedings), 80(2), May, pp. 350-4.

Mokyr, Joel (1996) 'Evolution and Technological Change: A New Metaphor for Economic History?' in Robert Fox (ed.) Technological Change (London: Harwood), pp. 63-83.

Mokyr, Joel (2006) 'Useful Knowledge as an Evolving System: The View from Economic History', in Lawrence E. Blume and Steven N. Durlauf eds., The Economy as an Evolving Complex System. Vol. III: Current Perspectives and Future Directions (Oxford and New York: Oxford University Press), pp. 307-337.

Nelson, Richard R. (1991) 'Why Do Firms Differ, and How Does it Matter?', Strategic Management Journal, 12, Special Issue, Winter, pp. 61-74.

Nelson, Richard R. (1995) 'Recent Evolutionary Theorizing About Economic Change', Journal of Economic Literature, 33(1), March, pp. 48-90.

Nelson, Richard R. (2007) 'Universal Darwinism and Evolutionary Social Science', Biology and Philosophy, 22(1), January, pp. 73-94.

Nelson, Richard R. and Winter, Sidney G. (1982) An Evolutionary Theory of Economic Change (Cambridge, MA: Harvard University Press).

Neumann, John von (1966) Theory of Self-Reproducing Automata, ed. and completed by Arthur W. Burks (Urbana: University of Illinois Press).

Price, George R. (1970) 'Selection and Covariance', Nature, 227, pp. 520-1.

Price, George R. (1995) 'The Nature of Selection', Journal of Theoretical Biology, 175, pp. 389-96.

Prusiner, Stanley B. (1998) 'Prions', Proceedings of the National Academy of the Sciences, 95, November, pp. 13,363-13,383.

Richards, Robert J. (1987) Darwin and the Emergence of Evolutionary Theories of Mind and Behavior (Chicago: University of Chicago Press).

Ritchie, David G. (1896) 'Social Evolution', International Journal of Ethics, 6(2), pp. 165-81.

Rose, Steven (1997) Lifelines: Biology, Freedom, Determinism (London: Allen Lane).

Saviotti, Pier Paolo (1996) Technological Evolution, Variety and the Economy (Aldershot: Edward Elgar).

Segerstråle, Ullica (2000) Defenders of the Truth: The Sociobiology Debate (Oxford: Oxford University Press). 
Simon, Herbert A. (1957) Models of Man: Social and Rational. Mathematical Essays on Rational Human Behavior in a Social Setting (New York: Wiley).

Somit, Albert and Peterson, Steven A. (1992) The Dynamics of Evolution: The Punctuated Equilibrium Debate in the Natural and the Social Sciences (Ithaca, NY: Cornell University Press).

Sperber, Dan (1996) Explaining Culture: A Naturalistic Approach (Oxford: Basil Blackwell).

Sperber, Dan (2000) 'An Objection to the Memetic Approach to Culture', in Aunger, Robert (ed.) (2000) Darwinizing Culture: The Status of Memetics as a Science (Oxford and New York: Oxford University Press), pp. 162-73.

Sterelny, Kim, Smith, Kelly C. and Dickison, Michael (1996) 'The Extended Replicator', Biology and Philosophy, 11, pp. 377-403.

Szathmáry, Eörs (2000) 'The Evolution of Replicators', Philosophical Transactions: Biological Sciences, 355, no. 1403, November 29, pp. 1669-1676.

Tushman, Michael L. and Romanelli, Elaine (1985) 'Organizational Evolution: A Metamorphosis Model of Convergence and Reorientation', Research in Organizational Behavior, 7, pp. 171 - 222.

Vanberg, Viktor J. (1994) 'Cultural Evolution, Collective Learning and Constitutional Design', in Reisman, David (ed.) Economic Thought and Political Theory (Boston, Dordrecht, London: Kluwer Academic Publisher), pp. 171-204.

Vanberg, Viktor J. (1997) 'Institutional Evolution through Purposeful Selection: The Constitutional Economics of John R. Commons', Constitutional Political Economy, 8, pp. 105-122.

Vanberg, Viktor J. (2002) 'Rational Choice versus Program-Based Behavior: Alternative Theoretical Approaches and Their Relevance for the Study of Institutions', Rationality and Society, 14(1), Summer, pp. 7-53.

Vanberg, Viktor J. (2004) 'The Rationality Postulate in Economics: Its Ambiguity, Its Deficiency and Its Evolutionary Alternative', Journal of Economic Methodology, 11(1), March, pp. 1-29.

Vanberg, Viktor J. (2006) 'Human intentionality and design in cultural evolution', in Christian Schubert, Georg von Wangenheim (eds) (2006) Evolution and Design of Institutions (London und New York: Routledge), pp. 197-212.

Veblen, Thorstein B. (1899) The Theory of the Leisure Class: An Economic Study in the Evolution of Institutions (New York: Macmillan).

Veblen, Thorstein B. (1914) The Instinct of Workmanship, and the State of the Industrial Arts (New York: Macmillan).

Witt, Ulrich (2003) The Evolving Economy: Essays on the Evolutionary Approach to Economics (Cheltenham UK and Northampton MA: Edward Elgar).

Witt, Ulrich (2004) 'On the Proper Interpretations of "Evolution" in Economics and its Implications for Production Theory', Journal of Economic Methodology, 11(2), June, pp. 125-46.

Witt, Ulrich (2006) 'Evolutionary Concepts in Economics and Biology', Journal of Evolutionary Economics, 16(5), December, pp. 473-76. 